\title{
The Value of Big Data to the World Economy
}

\author{
Dr. Marwa SalahEldin Fahmy \\ Lecturer at the Sadat Academy \\ Arab Republic of Egypt
}

\begin{abstract}
The word represents the new revolution in the world economy. The value and the problems of big data, both, stems from the analytical requirements to make this big data useful and change it from a curse to a blessing. This paper presents the vision of the author of the relationship between big data and their impact on both companies and countries economy. It tries to answer the question "do big data impact economies? And if it does, how does it do it?".
\end{abstract}

Keywords: Econometrics, Economic Indicators, Economic Analysis-Economy, e-Commerce, Big Data, Big Data Analysis, Computer Databases and Database Design, Economic Indicators.

\section{Introduction}

The rationale behind this research was derived from the fact that the value of big data added more power to information and that power became obvious. That is because; big data is enabling organizations to employ and to analyzeaccumulated data in new ways. Now, with the help of today's technology, big data is helping to transform businesses, industry, government services and people's lives.

Mistakenly, people think of big data in the context of size only, but in fact, big data refers to the sheers amount of analysis of that data and the speed at which information is created from that data.

One of the important sources of big data is loT, which added to the capabilities of big data new power. The opportunities posed by the loT are huge, and they have the potential, to revolutionize the way businesses and governments operate, and the way people live.

Section two presents research hypotheses, research questions and research methodology. Section three discusses some basic concepts of big data. Section four presentsthe way economy data can be used as a source of Big Data. Section five explains the value of big data to world economy. In section six, estimates of the aggregate value of big data analyticswas presented. The paper conclusion and future works is discussedin section seven.

\section{Research hypotheses, research questions and research methodology}

This section presents research hypotheses, the main research question and research methodology According to Kothari researcher should explain why he or she is using a method or technique and why his not using others so that research results are capable of being evaluated either by the researcher himself or by others (Kothari, 2004).

* This article was submitted in April 2018, accepted for publishing in September 2018 and published on December 2020.

(c) Arab Administrative Development Organization- League of Arab States, 2020, pp 307-322، DOI: $10.21608 /$ aja.2020.131054 


\section{Research hypotheses}

This research hypothesis is:

"As big data has become one of the most effective factors in world economy, it will be a major player in the world economy in the future".

This research presumes that as legacy data accumulates in organizations will prove to be a vital economic power for both organizations and countries.

The research hypothesis implies that as analytical methods of data from different sources which are diversified covering many data sources, social, economic and political, the effect of big data on the success or failure of organizations will be judged in some way by its ability to collect and analyze data to influence economic factors.

From that since this research proposes that as time passes and data are growing the following matters will occur:

- A positive increase of developments of software applications that are specialized in analyzing big data in order to calculate tendencies and trends of economic indicators.

- A positive added value of big data will increase exponentially having big data itself to be a commodity with ever increasing value.

- A positive relationship between data size increase and increase in big data access regulations.

- A positive relationship between data size increase and increase of investments in protection mechanisms of the users of social applications will be strengthened.

\section{Research questions}

Based on the research problem definition given above the goal of this research is given to offer empirh ical evidence and answer to the main question of this research: "How big data may influence the world economy?" In order to answer this question, of this research by answering several Sub-questions :

- What is big data mean?

- What is the big data life cycle?

- What challenges come with big data?

- How economy data become a source of Big Data?

\section{Research methodology}

Research methodology is a process used to collect information and data for further steps of analysis and drawing a conclusion. when a researcher discusses concerning research methods, he is not only discussing the research methods but also deliberates on the logic behind the selected methods in the context of this research. This research will depend on quantitative methods are normally used when the research questions are already pre-established, so its objective is testing the ideas that have been proposed (Baarda, 2010). And to collect data from secondary sources, which is defined as that data which has already been collected by someone else and published or defined somewhere, which includes: published articles, research papers, published books, prior research, relevant papers or journals, magazine, etc. (Kumar, 2010) to answer the research questions.

\section{Research approach}

In this research, a deductive research approach is designed. This approach begins with generalized theories and works towards a more specific theory. In the research, some clear expectations are drawn based on 
the existing literature on the subject under study. Finally, the new expectations are evaluated in comparison with the empirical evidence, and finally, it would be accepted or rejected (Sneider \& Larner, 2009).

\section{What is big data?}

Under the tremendous increase of global data, the term Big Data has emerged to describe enormous datasets. The National Institute of Standards and Technology (NIST) define Big Data, as:

"Big data shall mean the data of which the volume, acquisition speed, or data representation limits the capacity of using traditional relational methods to conduct effective analysis".

\section{Some basic concepts of big data}

The real value of big data to economists comes from data analysis; the problem is in the existing methods used to analyze data. That showed the need for efficient methods or technologies be used to analyze and process big data [1,2]. The potential volumes of data are forecasted in the IDC (International Data Corporation) report. That report predicts that the total volume of enterprise data is expected to grow at the rate of $50 \%$ each year. By 2020, IDC predicts that the volume of data will reach around 40 Zettabytes; taking into account that a Zettabyte is $\left(10^{21}\right.$ bytes $)$ or in numbers $(1000,000,000,000,000,000,000)$ bytes [2]. New sizes required new units to measure those sizes

\section{Newmeasurement units to represent bigger data sizes}

The largest storage devices in the world are built by a company named $\left(\mathrm{EMC}^{2}\right)$. The company responded to the IDC's study and presented new devices capable of dealing with the exploding data sizes. Those devices use new unit sin reflection to that increase, and units to measure data sizes have changed too. Figure (1) presents the global storage capacity. Table (1) shows the different names of each one of storage sizes. As the table is presenting, today Information Technology (IT) industry is talking about data sizes in $\left(\mathbf{1 0}^{\mathbf{3 1}}\right)$ bytes "and increasing by the second".

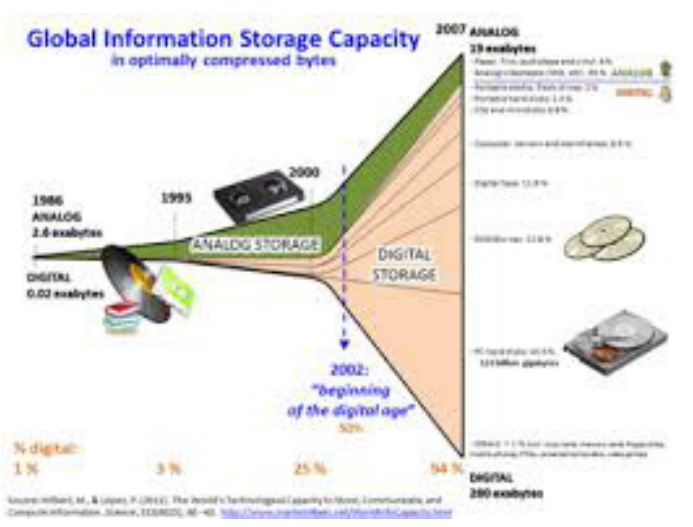

\section{Definitions of big data}

Figure 1

There are several definitions of the term big data. This section presents the most commonly used definitions.

The IDC in 2011 [3], defined big data Big Data as being not so much about the content that Big Data is that is created, nor is it even about consumption. It is more about the analysis of the data and how that needs to be done. It is not really a 'thing', but instead a dynamic/activity that crosses many IT borders. IDC defines Big Data in this way:

\begin{tabular}{|l|ll|}
\hline \multicolumn{3}{|c|}{ Table (1) } \\
\hline 1 & \multicolumn{1}{|c|}{ Nyte } & S bits. \\
2 & Kilo & 1024 Bytes $-10^{3}$ \\
3 & Megabyte & $(1000000$ Bytes $)-10^{6}$ \\
4 & Gigabyte & $(1000000000$ Bytes $)-10^{9}$ \\
\hline 5 & Terabyte & $(1000000000000$ Bytes $)-10^{12}$ \\
\hline 6 & Petabyte & $(1000000000000000$ Bytes $)-10^{15}$ \\
\hline 7 & Exabyte & $(1000000000000000000$ Bytes $)-10^{18}$ \\
\hline 8 & Zettabyte & $(1000000000000000000000$ Bytes $)-10^{21}$ \\
9 & Yottabyte & $(1000000000000000000000000$ Bytes $)-10^{24}$ \\
10 & Xenottabyte & $(1000000000000000000000000000$ Bytes $)-10^{27}$ \\
\hline 11 & Shilentnobyte & $(1000000000000000000000000000000$ Bytes $)-10^{30}$ \\
\hline 12 & Domegemegrottebyte & $(1000000000000000000000000000000000$ Bytes $)-10^{33}$ \\
\hline
\end{tabular}


"Big Data technologies describe a new generation of technologies and architectures, designed to economically extract value from very large volumes of a wide variety of data, by enabling high velocity capture, discovery and/or analysis."

: Defining 'Big Data'

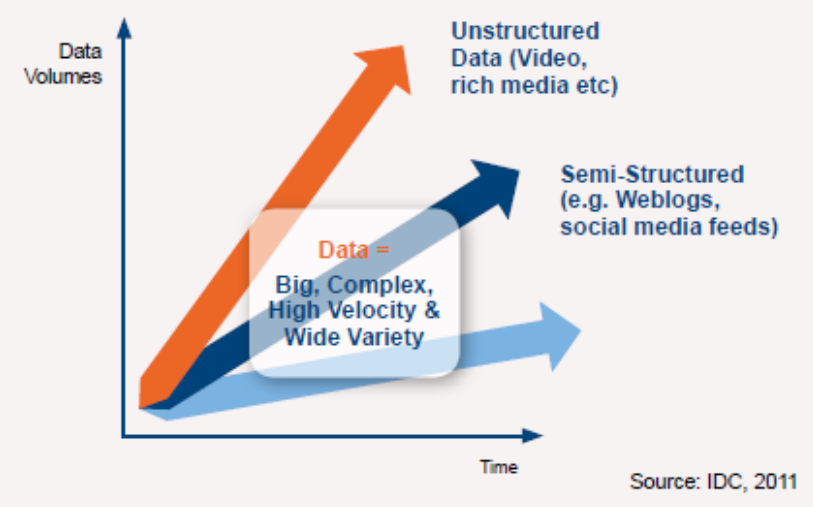

Global Mobile Data - Traftic growth \& forecast ferabstes per manti)

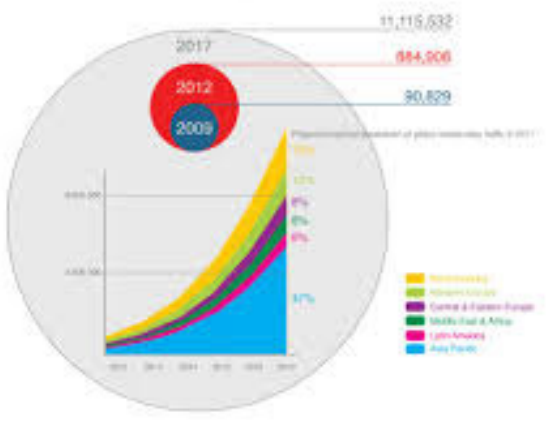

Figure 2- Complexity of Big Data

Source: IDC Report, 2012

In a 2001 research report [4] and related lectures, META Group (now Gartner) analyst Doug Laney defined data growth challenges and opportunities as being three-dimensional, i.e. increasing volume (amount of data), velocity (speed of data in and out), and variety (range of data types and sources).

Gartner, and now much of the industry, continue to use this "3Vs" model for describing big data. [5] In 2012, Gartner updated its definition as follows: "Big data is high volume, high velocity, and/or high variety information assets that require new forms of processing to enable enhanced decision making, insight discovery and process optimization."

Gartner's definition of the $3 V_{s}$ is still widely used, and in agreement with a consensual definition that states that "Big Data represents the Information assets characterized by such a High Volume, Velocity and Variety to require specific Technology and Analytical Methods for its transformation into Value". [6] Additionally, a new V "Veracity" is added by some organizations to describe it, [7] revisionism challenged by some industry authorities. [8] The $3 \mathrm{~V}$ s have been expanded to other complementary characteristics of big data: [9] [10]

Therefore, in most cases big data is defined through these $3 \mathrm{~V}$ 's of big data. As show in figure 3 , big data is usually determined by 3 equally important factors. The combination of the 3 is what makes big data different from the traditional data. (Beyer, 2011)

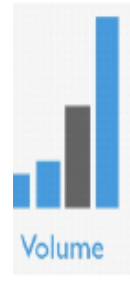

lore Volume hat could fit in a single database
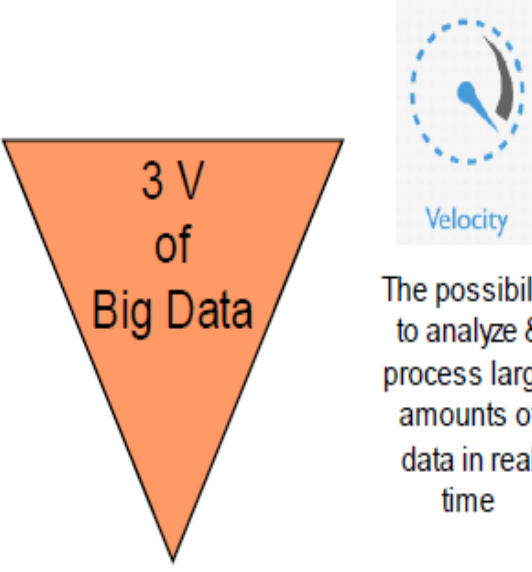

The possibility to analyze \& process large amounts of data in real time

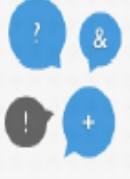

Combination of data from various sources\& different 
Volume: Volume simply describes the sired volume of big data and the possibility to store and analyze larger sets of data than ever before. Through volume a better and more detailed insight into an issue is created.

Velocity: Velocity describes the technological capabilities to collect and analyze data in real time. technology nowadays enables us to get insights into data in real time. With the new technology we are able to analyze data in real time.

Variety: the most crucial element of big data is variety. Variety describes in general the diversity of data. The multitude of sources of data, giving us the possibility to interconnect different data sets and derive conclusions from it.

Life-cycle of Data: Most application scenarios require real-time performance of the big data analytics. There is a need to define the life cycle of the data, the value it can provide and the computing process to make the analytics process real time, thus, increasing the value of the analysis (Chen \& others, 2014). Big data is always not always better, hence proper data filtering techniques can be developed to ensure correctness in the data (Boyd \& Crawford, 2012). Another big issue is related to the availability of data that is complete and reliable. In most of the cases, data are sparse and do not show clear distribution, yielding misleading conclusions. A method to overcome these problems needs proper attention and sometimes handling of unbalanced data sets leads to biased conclusion

\section{Economy data as a source of big data}

To imagine what is happing today, let me remind you that We sent men to the moon in 1969 on a tiny fraction of the data that's in the average laptop. Big data have come from several sources those sources are:

1- Machine generated data.

2- The digital universe.

3- Digital sensors.

4- The Internet of Things.

\section{Machine generated data}

Figure 4 presents key predictions by IDC included: that by 2020, one tenth of the world's data will be produced by machines; that the amount of useful data produced will increase from 22\% in 2013 to more than 35\% in 2020; most of the world's data will be produced in emerging markets; the amount of data that spends some of its lifetime in the cloud will double; and the amount of data will increasingly outpace available storage [11].

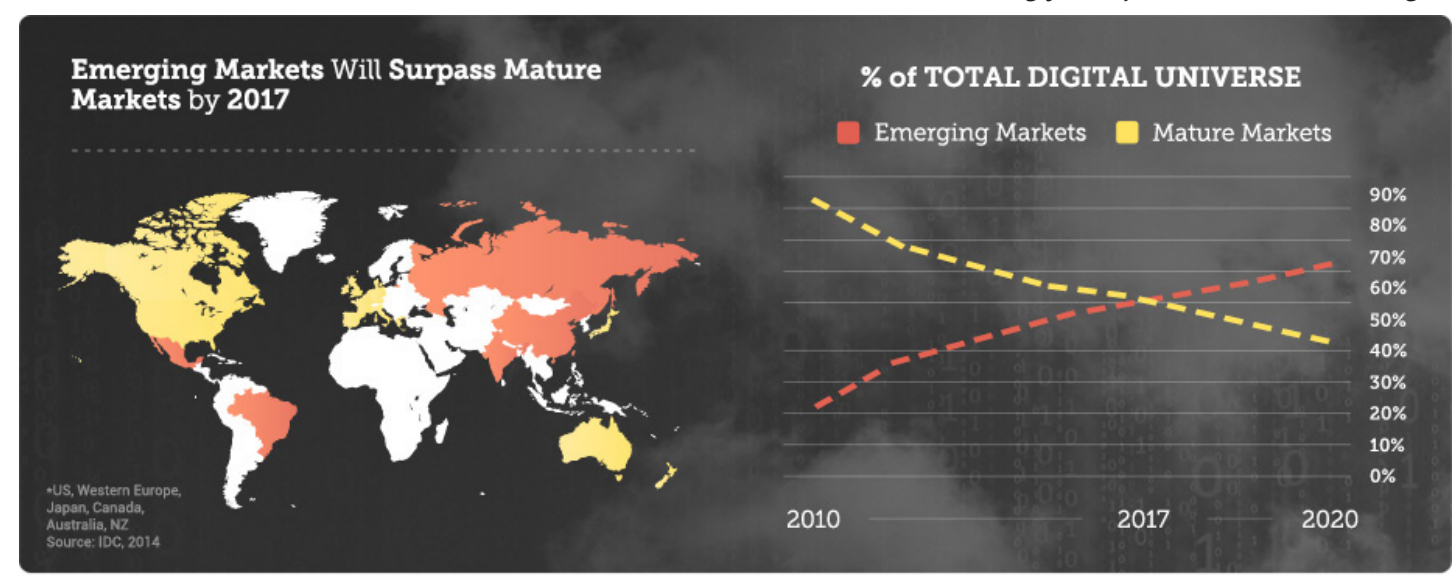

Figure 4- Machine generated data as \% in digital universe 


\section{The digital universe}

There have been three major growth revolutions for the digital universe in modern world. The first was when digital camera technology replaced film; the second, when analog telephony went digital; and the third, when TV went digital.

In fact, digital universe is created by everyone using a digital device. Those devices vary from computers to digital music recorders and digital cameras, today there are more than 2 billion people and millions of enterprises living their lives and doing their work online, [12] Examples might include:

1- Oscars-host Ellen DeGeneres' "celeb selfie" tweet that was viewed 26 million times across the Web during a 12-hour period;

2- the more than one billion hours of TV shows and movies streamed from Netflix per month;

3- And the data streaming at 2.8 Gigabytes per second from the Australian Square Kilometer Array Pathfinder (ASKAP) radio telescope.

Figure five, shows that the digital universe is currently huge but still growing exponentially. It predicts that if the digital universe were represented by the memory in a stack of tablets, in 2013 it would have stacked two thirds the way to the moon. By 2020, there would be 6.6 stack from the earth to the moon. In memory sizes, in 2013, data sizes were measured at (4.4 ZB), by 2020 it is expected to be (44 ZB).

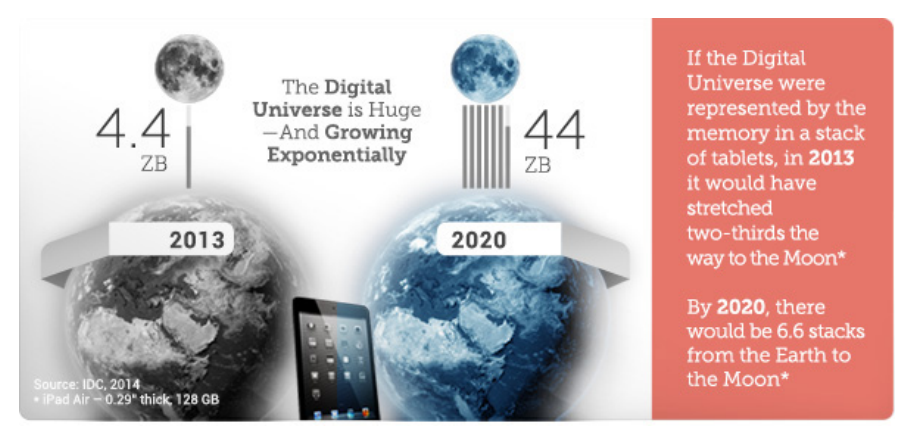

Figure 5 Forecasts of digital universe

\section{Digital sensors}

Digital sensors are Millions of millions receptors that collect and retransmit data between communicating devices. They are active devices that keep sending and receiving data over and the Internet in general and private digital networks in particular. Examples digital sensors include:

1- Car sensors grid covering all Europe.

2- Data collected by sensors connected to giant power generation stations.

3- Data collected by sensors connected to gas turbines and gas pipes.

Car sensors allowed the implementation of autonomous cars (Self driven cars). Sensors connected to giant power generation stationswhenanalyzed, made electricity cheaper and cleaner. Gas turbines and gas pipes sensors, monitor gas flow making gas industry safer.

\section{The Internet of Things (IoT)}

The Internet of Things ( $\mathrm{IOT}$ ) in its simplest understanding is connecting everything in life to the internet. That connection triggered the migration of analog functions monitoring and managing the physical world to digital functions involving communications and software telemetry. It is abbreviated by the advent (loT). loTis considered by many as the new industrial revolution and the future of digital world. That is because it is fed by sensors growing in numbersby the trillions, working with intelligent systems in the billions, and involving millions of applications. 
According to the International Data Council (IDC) report, loT represents a revolution due to the fact that while there is a finite number of things - at least big things - that might be computerized which is already approaching 200 billion, the number of sensors (e.g., the accelerometer in your smart phone) that track, monitor, or feed data to those things is already more than 50 billion, with scientists talking about trillion-sensor networks within 10 years. Notice that while not all of those 200 billion things are actually wired and communicating on the Internet, there are around 20 billion are. And, by 2020, this number is expected to grow by $50 \%$ to 30 billion connected devices.

$\mathrm{EMD}^{2}$, found the number of everyday objects connected to the internet and able to automatically record, report and receive data - the so-called internet of things - is approaching 200 billion todays, with $7 \%$ (or 14 billion) already connected to and communicating over the internet. That figure currently represents $2 \%$ of the world's data. IDC forecasts that, by 2020 , the number of connected devices will grow to 32 billion and comprise $10 \%$ of the world's data figure 5 .

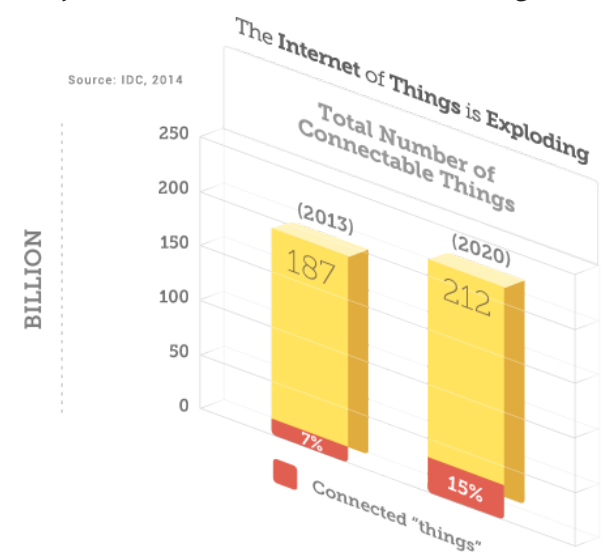

IoT Embedded Systems as \% of the DU

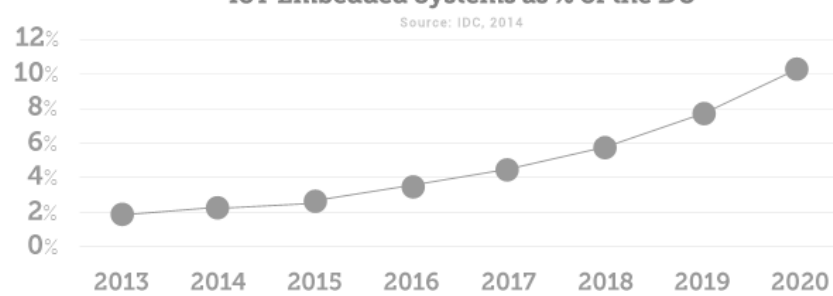

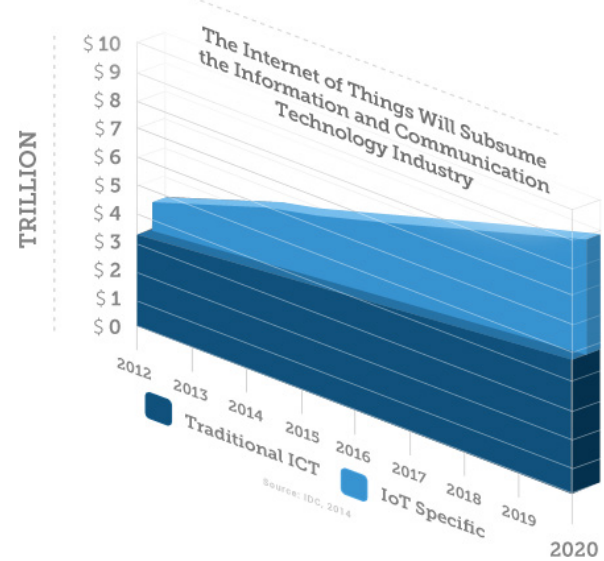

\# of Information "Containers" in the DU

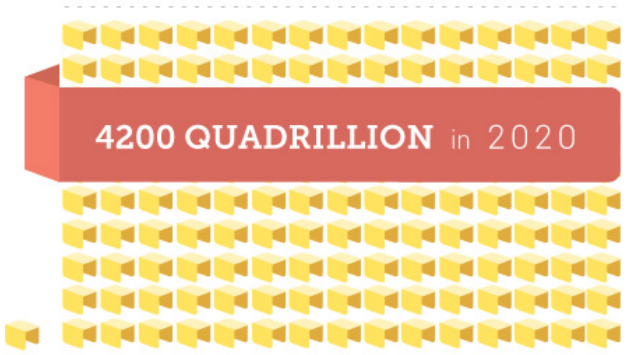

28 QUADRILLION in 2010

Figure 6- Growth forecast of Internet of Things (IoT)

\section{The value of big data to world economy}

Economists, similar to all other useful things, discovered the value of big data. After in depth research, McKinsey \& Company in [13] as presented in figure 6,observed how big data created values in many sectors, those sectors are:

- The U.S. healthcare systems,

- The EU public sector administration,

- The U.S. retail,

- The global manufacturing,

- The global personal location data. 
In that report, a research on the five core industries that represent global economy was presented, that report the research pointed out that big data may give a an extensive value to the following economic areas:

- Different economic functions,

- Improve the productivity and competitiveness of enterprises and public sectors,

- Create huge benefits for consumers.

From that sense, big data could create additional value if the following conditions are satisfied:

If big data administrative manage to do the following:

- Create effective models to represent big data,

- Manage the effective utilization of big data,

- Improve efficiency and quality of big data.

The potential value of the big data:

- U.S medical industry gained through data as presented in [14]:

- May surpass USD 300 billion,

- Reduce the expenditure for the

U.S. healthcare by over $8 \%$;

- Additionally, retailers that fully utilize big data willimprove profit bymore than 60\%;

- Improve the efficiency of government operations,

- The economies in Europe could save over EUR 100 billion.

\section{Estimates of the aggregate value of big data analytics}

In [14], estimates of the aggregate value of big data analytics and the loT were presented. It suggests in Table 2 , that over the next five years (2015 to 2020), the value to the UK economy of big data analytics and the loT combined could accumulate to $£ 322$ billion and that is as expressed in 2015 prices.

If those numbers are further interpreted, they mean:

- This is roughly equivalent to an average of $£ 54$ billion per year, or $2.7 \%$ per year of annual GDP

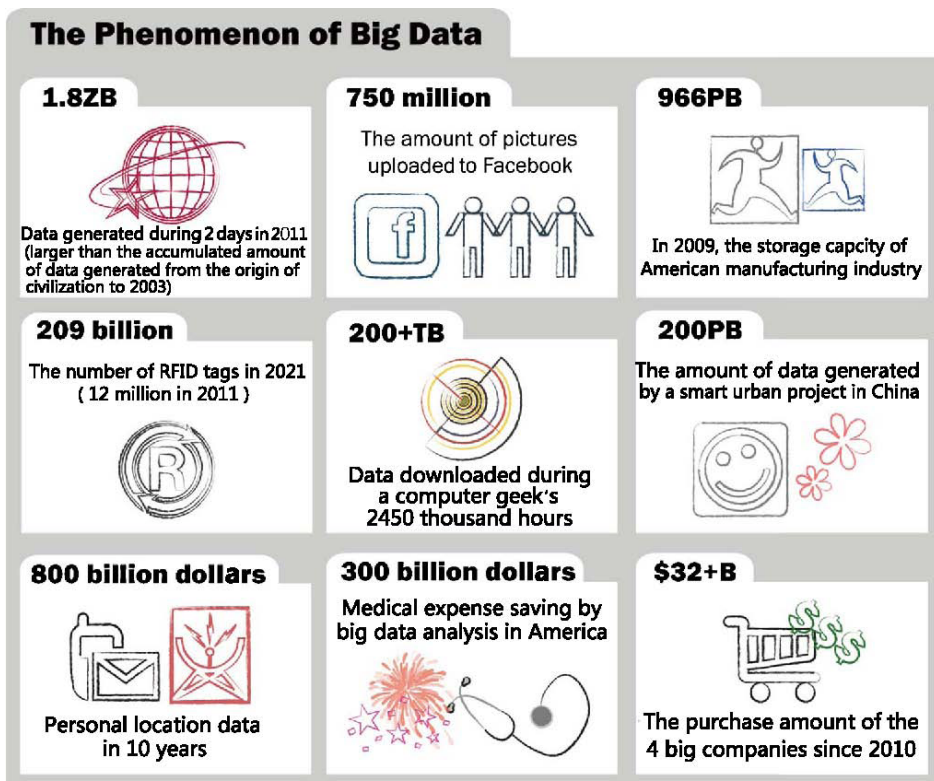

"Data are becoming the new raw material of business: Economic input is almost equivalent to capital and labor" $-<<$ Economist $\gg>, 2010$

“Information will be "the 21th Century oil.” - Gartner company, 2010

Figure 7

Table 2

\begin{tabular}{l|ccc|}
\hline $\begin{array}{l}\text { Combined impacts } \\
\text { of big data and the } \\
\text { Internet of Things }\end{array}$ & $\begin{array}{c}2015 \\
\text { Economic } \\
\text { benefits } \\
(\mathrm{fm})\end{array}$ & $\begin{array}{c}2020 \\
\text { Economic } \\
\text { benefits } \\
(\mathrm{fm})\end{array}$ & $\begin{array}{c}2015-2020 \\
\text { Cumulative } \\
\text { economic } \\
\text { benefits }(\mathrm{fm})\end{array}$ \\
\hline $\begin{array}{l}\text { Absolute GDP } \\
\text { contributions }\end{array}$ & 46,124 & 61,814 & 322,211 \\
$\begin{array}{l}\% \text { contribution to } \\
\text { GDP }\end{array}$ & $2.1 \%$ & $3.0 \%$ & $2.7 \%$ (avg. p.a.) \\
\hline & & & Source: Cebr analysis
\end{tabular}


between 2015 and 2020 .

- This is equivalent to twice the size of the combined education, NHS and defense budgets for 2014-2015,

- And over one-fifth (22\%) of the size of the UK's net public debt (of c. $£ 1.5$ trillion in 2014/15).

In this paper, the relationship between Big Data and Economy are expressed in the terms of:

- Total 'data equity' estimates.

- Business efficiency benefits.

\section{Total 'data equity' estimates in 2015}

There are successful companies, such as Amazon and Google, where data analytics are the foundation of the enterprise. But, for most legacy companies, success in data analytics has been limited to a few tests or to narrow slices of the business, with very few firms achieving a significant impact from big data. McKinsey's survey [14] found that three-quarters of analytics' leaders had achieved revenue or cost improvement through big data of less than $1 \%$.

This suggests that, while more businesses are storing big data, they are yet to utilize them to their full potential and are therefore yet to realize their full impacts. These findings are not inconsistent with the results of this study.

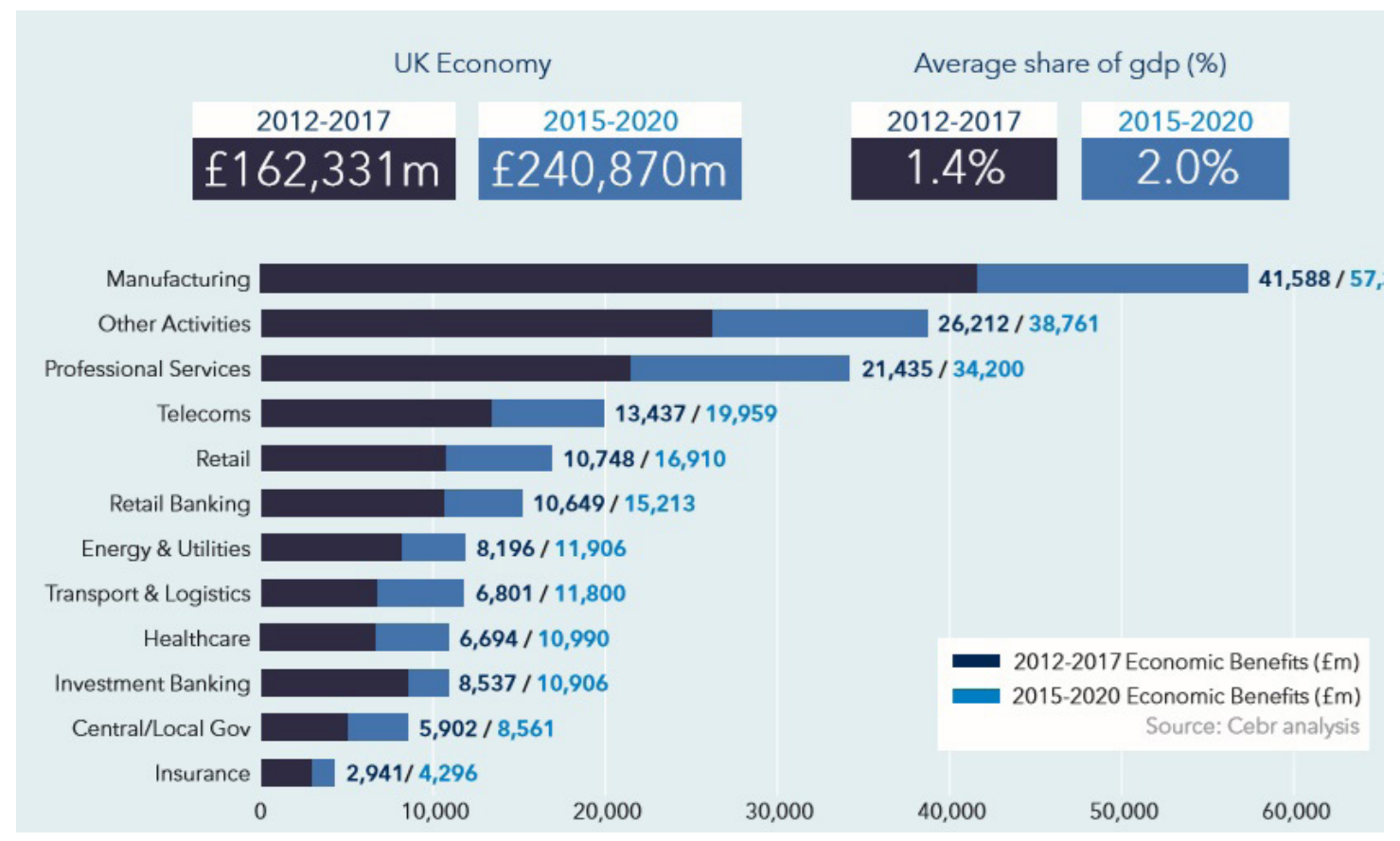

Figure 8

Source: Cebr analysis

Figure 8, illustrates that between 2012 and 2017, the total equity benefit of big data analytics will be as follows:

- Is expected to total $£ 162$ billion, or on average $£ 27$ billion per year.

- This is equivalent to roughly $1.4 \%$ of GDP per year.

- An estimate of $2.5 \%$ of GDP per year. 


\section{Business efficiency benefits}

This paper means by the term "efficiency benefits"that a business processes becomes more cost effective through having the following parameters:

- Better customer intelligence and fraud detection,

- Improved supply chain,

- Better performance,

- Better quality,

- Better risk management.

Big data analytics contribute to all of the above where Big data analytics result in savings through these channels in turn lead to enhanced output and value added.

Figure 9 sets out the cumulative economic benefits arising from business efficiency gains over the periods 2012-17 and 2015-20.

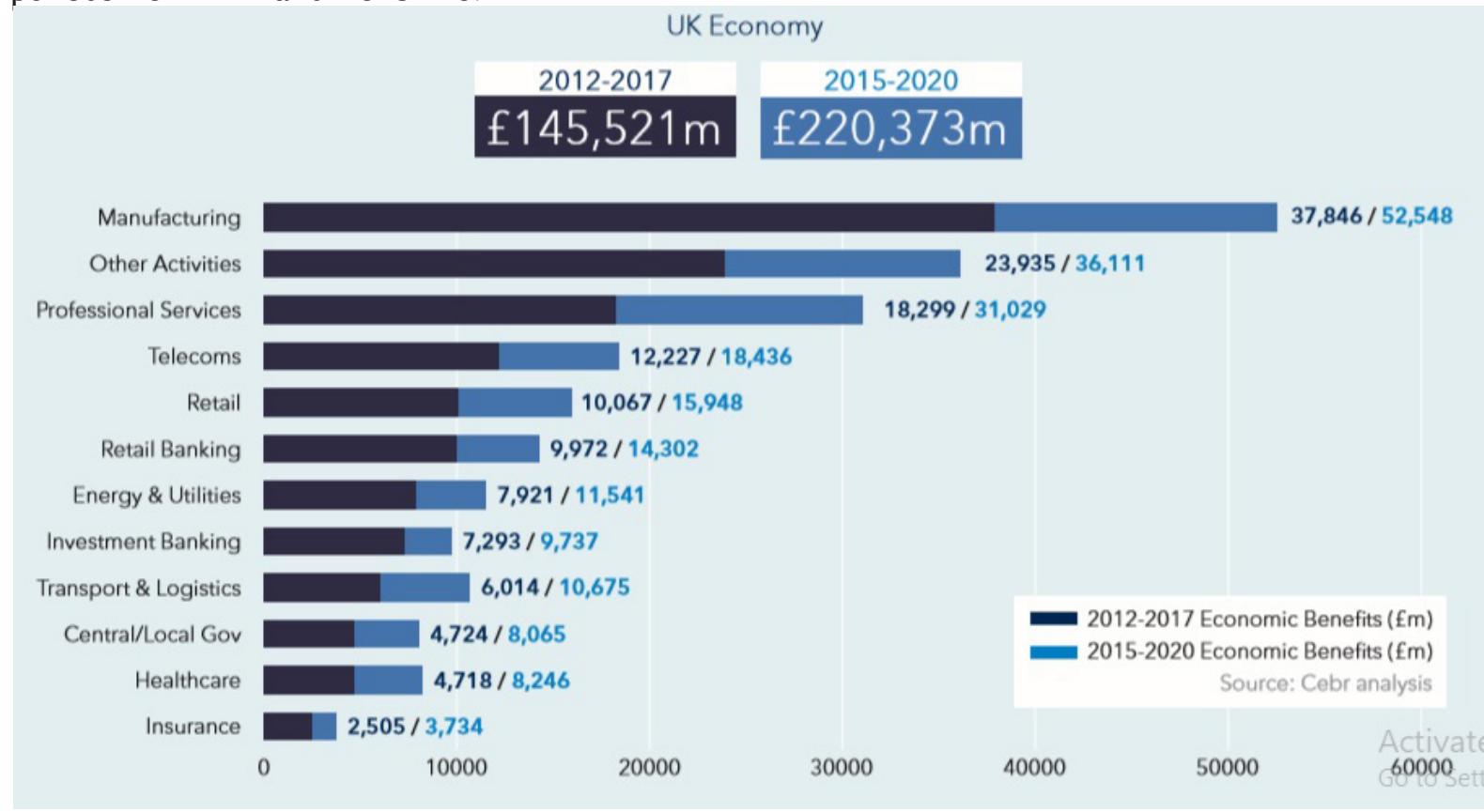

Figure 9- Cumulative economic benefits arising from business efficiency gains over the periods 2012-2017 and 2015-2020

Source: Cebr analysis

\section{1- Customer intelligence}

Big data allow better insight into customer intelligence. Table 3 illustrates the cumulative 2012-17 and 2015-20 customer intelligence efficiency benefits.

\section{2- Supply chain management}

Big data analytics enable businesses to make significant cost savings through better supply chain management. Table 4 refreshes the 2012-17 efficiency benefits for supply chain intelligence, alongside the benefits over the period 2015- 20.

Manufacturing sector is the largest beneficiary from Big data analytics in the area of Supply chain management; it is expected to experience $£ 8$ billion in efficiency gains through the supply chain management 
Table 4-Supply chain management

\begin{tabular}{|lcc|}
\hline & $\begin{array}{c}\text { Cumulative } \\
2012-17(\mathrm{fm})\end{array}$ & $\begin{array}{c}\text { Cumulative 2015- } \\
20(\mathrm{fm})\end{array}$ \\
\hline Manufacturing & 6,156 & 8,547 \\
\hline Other Activities & 3,806 & 5,742 \\
\hline Professional Services & 2,069 & 3,509 \\
\hline Energy \& Utilities & 1,685 & 2,455 \\
\hline Telecoms & 1,653 & 2,492 \\
\hline Retail & 1,458 & 2,310 \\
\hline Retail Banking & 1,432 & 2,054 \\
\hline Investment Banking & 1,356 & 1,811 \\
\hline Transport \& Logistics & 971 & 1,724 \\
\hline Healthcare & 573 & 1,002 \\
\hline Insurance & 482 & 718 \\
Central/Local Government & 401 & 685 \\
UK Economy & 22,043 & 33,049 \\
\hline Soltiva & & \\
\hline
\end{tabular}

Table 3- Customer intelligence

\begin{tabular}{lcc|}
\hline & $\begin{array}{c}\text { Cumulative } \\
2012-17(\mathrm{fm})\end{array}$ & $\begin{array}{c}\text { Cumulative 2015- } \\
20(\mathrm{fm})\end{array}$ \\
\hline Manufacturing & 9,499 & 13,188 \\
\hline Other Activities & 6,961 & 10,503 \\
Professional Services & 5,942 & 10,075 \\
Telecoms & 3,646 & 5,498 \\
Retail & 3,593 & 5,691 \\
Retail Banking & 2,713 & 3,892 \\
Energy \& Utilities & 2,147 & 3,128 \\
Investment Banking & 1,734 & 2,315 \\
Transport \& Logistics & 1,696 & 3,010 \\
Central/Local Government & 1,300 & 2,219 \\
Healthcare & 1,059 & 1,850 \\
Insurance & 831 & 1,239 \\
UK Economy & 41,120 & 62,609 \\
\hline Source: Cebr analysis & & 60105 \\
\hline
\end{tabular}

Source: Cebr analysis

mechanism over the period 2015-20. The central/local government sector is expected to benefit the least through this channel, by a significant margin.

\section{3- Risk management}

Big data analytics of risk management are expected to contribute a cumulative $£ 38$ billion in efficiency savings across the business economy in the period 2012-17. It is forecasted to reach $£ 58,023$ billion in the period of 2015-2020

\section{4- Performance management}

The total efficiency benefits from performance management improvements through the use of big data analytics are expected to amount to a cumulative $£ 9$ billion in the period 2012-2017 and forecasted to be $£ 14$ billion in the pet riod 2015-2020.Table 6 presents the economic benefits from performance management analytics over the periods 2012-17 and 2015-20.

\section{5- Fraud detection}

Big data analytics allow better fraud detection that could total $£ 290$ million in the period 20152020. Table 7, presents fraud detection efficiency benefitsin the periods of 2012-17 and a forecast of the period of 2015-20.

\begin{tabular}{|c|c|c|}
\hline & $\begin{array}{c}\text { Cumulative 2012-17 } \\
\text { (fm) }\end{array}$ & $\begin{array}{c}\text { Cumulative 2015- } \\
20(\mathrm{fm})\end{array}$ \\
\hline Manufacturing & 9,499 & 13,188 \\
\hline Other Activities & 6,505 & 9,815 \\
\hline Professional Services & 5,541 & 9,396 \\
\hline Telecoms & 3,188 & 4,806 \\
\hline Retail Banking & 2,843 & 4,077 \\
\hline Energy \& Utilities & 2,147 & 3,128 \\
\hline Retail & 2,039 & 3,229 \\
\hline Investment Banking & 1,734 & 2,315 \\
\hline Transport \& Logistics & 1,674 & 2,972 \\
\hline Healthcare & 1,279 & 2,235 \\
\hline Central/Local Government & 1,153 & 1,969 \\
\hline Insurance & 599 & 893 \\
\hline UK Economy & 38,200 & 58,023 \\
\hline
\end{tabular}

(Source: Cebr analysis) 


\section{Conclusion and future work}

To imagine the impact of big data on today's economy, a ship was sent to the moon in 1969 on a tiny fraction of the data that's in the average laptop [15]. Companies learnt the lessons, economics models have changed and new e-Commerce model have been presented. Some of those models are as follows:

- In 2015, when their profits dropped by $37 \%$, Samsung, decided to take the lead in this area and playing a leading role by investing billions in loT. They forecasted that the Internet of Things will drive new consumer and business behavior that will demand increasingly on intelligent industry solutions, which in turn, will drive trillions of dollars in opportunity for IT vendors and even more for the companies that take advantage of the loT. In fact, the game has worked and by the second quarter of 2016 they recovered their profit. By the end of the year 2017, Samsung profits exceeded (43\%).

- IBM, dropped its hardware policy and introduced the IBM intelligent cloud resembling human brain. By the end of 2017, this cloud has become a new world standard in cloud computing.

- Microsoft, has followed IBM and introduces the Microsoft cloud, by the end of 2017, this cloud became the main pillar in Microsoft profit generation machine.

- $\quad$ Amazon, made \$43.5 billion dollars net profit in the last quarter of 2017.

- Facebook, dominated electronic social media making \$45 billion profit from online activities.

Why Big data heralds a new era of economy is a matter of statistics. All earlier eras involved the economy of enterprises or people, before Big data there were a finite number both. Today, with Big data and its infinite sources, economy has to integrate and work in a tightly coupled manner with Information Technology. Economic models must involve the computerization, adding software and intelligence, to everything. Those things are varied from objects as large as supercomputers, airplanes, cars, and big turbines to households like refrigerators and dishwashers to objects as small as watches and toys leading to the connection of almost everything including cats and dog collars [16]. 
According to the IDC report 2013 some prospects of big data are:

- From 2013 to 2020, the digital universe will grow by a factor of 10 - from 4.4 trillion gigabytes to 44 trillion. It more than doubles every two years.

- Between 2013 and 2020 the division of the digital universe between mature and emerging markets (e.g., China) will switch - from 60\% accounted for by mature markets to $60 \%$ of the data in the digital universe coming from emerging markets.

- In 2013, two-thirds of the digital universe bits were created or captured by consumers and workers, yet enterprises had liability or responsibility for $85 \%$ of the digital universe.

- In 2013, only 22\% of the information in the digital universe would be a candidate for analysis, i.e., useful if it were tagged (more often than not, we know little about the data, unless it is somehow characterized or tagged - a practice that results in metadata); less than $5 \%$ of that was actually analyzed. By 2020, the useful percentage could grow to more than $35 \%$, mostly because of the growth of data from embedded systems.

- In 2013, while about $40 \%$ of the information in the digital universe required some type of data protection, less than $20 \%$ of the digital universe actually had these protections.

- Data from embedded systems, the signals from which are a major component of the Internet of Things, will grow from 2\% of the digital universe in 2013 to $10 \%$ in 2020 .

- In 2013, less than 20\% of the data in the digital universe is "touched" by the cloud, either stored, perhaps temporarily, or processed in some way. By 2020, that percentage will double to $40 \%$.

- Most of the digital universe is transient - unsaved Netflix or Hulu movie streams, or Xbox One gamer interactions, temporary routing information in networks, sensor signals discarded when no alarms go off, etc. - and it is getting more so. This is a good thing, because the world's amount of available storage capacity (i.e., unused bytes) across all media types is growing slower than the digital universe. In 2013, the available storage capacity could hold just 33\% of the digital universe. By 2020 , it will be able to store less than $15 \%$.

- $\quad$ In 2014, the digital universe will equal 1.7 megabytes a minute for every person on Earth.

This paper presented the impact and relationship between Big data and countries economy [17]. This paper has put more emphasis on the impact of big data on every aspect of live leading to a new revolution in different faces in life including economics models.

To imagine the impact of big data on today's economy, a space craft was sent to the moon in 1969 on a tiny fraction of the data that's in the average laptop. Today's average smart telephones are equipped with storage device with minimum of $32 \mathrm{Gbytes}$.

Companies learnt the lessons, economics models have changed and new e-Commerce model have been presented. Some of those models are as follows:

- In 2015, when their profits dropped by 37\%, Samsung, decided to take the lead in this area and playing a leading role by investing billions in loT. They forecasted that the Internet of Things will drive new consumer and business behavior that will demand increasingly on intelligent industry solutions, which in turn, will drive trillions of dollars in opportunity for IT vendors and even more for the companies that take advantage of the loT. In fact, the game has worked and by the second quarter of 2016 they recovered their profit. By the end of the year 2017, Samsung profits exceeded (43\%).

- IBM, dropped its hardware policy and introduced the IBM intelligent cloud resembling human brain. By the end of 2017, this cloud has become a new world standard in cloud computing.

- Microsoft, has followed IBM and introduces the Microsoft cloud, by the end of 2017, this cloud became the main pillar in Microsoft profit generation machine. 
- $\quad$ Amazon, made $\$ 43.5$ billion dollars net profit in the last quarter of 2017.

- Facebook, dominated electronic social media making $\$ 45$ billion profit from online activities.

This paper recommends that electronic economy, as an emerging new power, resting on large quantities of data should be considered. New economics models and new econometrics should be thought of to react to the extending electronic market and continually working sources of big data feeding in an everlasting manner.

In order to achieve all of the above, both governmental and private sector, have to perform the following tasks [18]:

- They have to make significant investments in applications with the objective of:

- Capturing data.

- Automating business processes.

- Improve operational efficiency.

- Harnessing analytics-led solutions.

- Apply field analysis in order to gain better customer insights.

- Building models to manage risk.

- Build software applications in order to make financial metrics more effective.

- Analyze big data to discover unique market differentiation.

Harnessing analytics-led solutions include several emerging technologies[19] such as:

- Cloud computing/ services.

- Social media data analysis.

- Online channels data analysis.

- Collaboration data including video and mobile data analysis.

- Computer networks data analysis.

That will require new sets of skills in several key categories [20]:

- Technical skills represented in the form of new class of technologies that are used to collect, process, discover and analyze massive data sets. That large volumes of data sets cannot be dealt with using traditional databases and computer architectures [21, 22].

- New type of business analyst statistician. This stems from the fact that traditional statisticians are dealing with data that they mostly know. With big data environment, systems are gathering data that may or may not be needed, from the perspective of analysis, this means 'statisticiandonot know the data $[23,24,25]$.

- Combining modern Al Techniques. The strength of this approach is originated from the reality that collected data are mostly unstructured data that the variables and analytical models are likely to be entirely new. Application of Al techniques means that there will be a way to re-think the methodsof analytical users will approach their work and it will offer a way of creating a 'Sandbox mentality' where discovery is always the starting point.

- So researcher wish to reinforce the necessity and responsibility of higher educational institute to incorporate modules and courses which develop the skills required to be able to understand, analyze and forecast with big data using variety of techniques. - and the importance of establishing big data driven organizational culture and capabilities to determines the level of benefits that organization generates from this technology.

- $\quad$ And suggest the necessity to make a big data project using big data and new technologies to deliver their mandate more effectively and efficiently due to the big data strong impact in every sector and today's industry. 


\section{References:}

- $\quad$ Bernard Marr. (2015). Big Data: 20 Mind-Boggling Facts Everyone Must Read, Forbes Report on Trends of Data Growth, Sep. 30, 2015

- Beyer, Mark. (2011). “Gartner Says Solving 'Big Data'Challenge Involves More Than Just Managing Volumes of Data". Gartner. Archived from the Original on 10 July 2011. Retrieved 13 July.

- Boyd, D. and Crawford, K. (2012). “Critical Questions for Big Data”, Information, Communication \& Society, 15:5, 662-679.

- $\quad$ Carter, Philip. (2011). Big Data Analytics: Future Architectures, Skills and Roadmaps for the CIO. IDC Report.

- $\quad$ Chen, M.; Mao, S. and Liu, Y. (2014). “Big Data: A Survey”, Mobile Networks and Applications, 19, (2), 171-209.

- Computing Community Consortium. (2011). Advancing Discovery in Science and Engineering. Spring 2011.

- De Mauro, Andrea; Greco, Marco and Grimaldi, Michele. (2016). “A Formal Definition of Big Data Based on its Essential Features". Library Review 65:122-135. doi:10.1108/LR-06-2015-0061.

- Diebold, F. (2012). On the Origin(s) and Development of the Term "Big Data". Pier working paper archive, Penn Institute for Economic Research, Department of Economics, University of Pennsylvania.

- González, Marta C.; César A. Hidalgo and Albert-László Barabási. (2008). Understanding Individual Human Mobility Patterns. Nature, 453, 779-782, $5^{\text {th }}$ June.

- Grimes, Seth. (2016). “Big Data: Avoid 'Wanna V' Confusion", Information Week, Retrieved $5^{\text {th }}$ January.

- Hilbert, M. (2015). Digital Technology and Social Change. [Open Online Course at the University of California] (freely available). https://www.youtube.com/watch.

- Hilbert, Martin. (2015). “Big Data for Development: A Review of Promises and Challenges. Development Policy Review", Martinhilbert.net. Retrieved 2015-10-07.

- Ibrahim; TargioHashem, Abaker; Yaqoob, Ibrar; BadrulAnuar, Nor; Mokhtar, Salimah; Gani, Abdullah; Ullah Khan, Samee. (2015). "big data" on Cloud Computing: Review and Open Research Issues", Information Systems, 47: 98-115. doi:10.1016/j.is.2014.07.006.

- Kumar, R. (2010). Research Methodology: A Step By Step Guide for Beginners. $2^{\text {nd }}$ ed. New Delhi: Pearson Education.

- Laney, Douglas. (2001). “3D Data Management: Controlling Data Volume, Velocity and Variety" (PDF). Gartner. Retrieved 6 February.

- $\quad$ Lazer, David and Others. (2009). Computational Social Science. Science, $6{ }^{\text {th }}$ Feb., 323 (5915), 721-723.

- $\quad$ Manyika, J.; McKinsey Global Institute; Chui, M.; Brown B.; Bughin, J.; Dobbs, R.; Roxburgh, C. and Byers, A. H. (2011) Big data: The Next Frontier for Innovation, Competition, and Productivity. McKinsey Global Institute .

- Manyika, James; Michael Chui; Brad Brown; Jacques Bughin; Richard Dobbs; Charles Roxburgh and Angela Hung Byers. (2011). Big Data: The Next Frontier for Innovation, Competition, and Productivity. McKinsey Global Institute. May. 
- Mayer-Sch“Onberger, V.; Cukier, K. (2013). Big Data: A Revolution That Will Transform How We Live, Work, and Think. Eamon Dolan/ Houghton Mifflin Harcourt

- National Science and Technology Council. (2011). Materials Genome Initiative for Global Competitiveness. June.

- Noguchi, Yuki. (2011). The Search for Analysts to Make Sense of Big Data. National Public RaR dio, Nov. 30, 2011. http://www.npr.org/2011/11/30/142893065/the-search-for-analysts-tomake-sense-of-big-data

- Prentice, Stephen, and Yvonne Genovese.(2011). Pattern-Based Strategy: Getting Value from Big Data. Gartner Group Press Release. July 2011. Available at http://www.gartner.com/it/page. jsp?id=1731916

- $\quad$ Snijders, C.; Matzat, U.; Reips, U.-D. (2012). “Big Data: Big Gaps of Knowledge in the Field of Internet", International Journal of Internet Science, 7: 1-5.

- Using Data for Systemic Financial Risk Management. Mark Flood, H. V. Jagadish, Albert Kyle, Frank Olken and Louiqa Raschid Proc. (2011). Fifth Biennial Conf. Innovative Data Systems Research, Jan. 